\title{
Photosynthetic Daily Light Integral During Root Development Influences Subsequent Growth and Development of Several Herbaceous Annual Bedding Plants
}

\author{
Veronica A. Hutchinson, Christopher J. Currey, and \\ Roberto G. Lopez ${ }^{1,2}$ \\ Department of Horticulture and Landscape Architecture, Purdue University, \\ 625 Agriculture Mall Drive, West Lafayette, IN 47907-2010
}

Additional index words. DLI, finish stage, flowering, light quantity, propagation

\begin{abstract}
Vegetatively propagated bedding plants are produced during the late winter and early spring when outdoor photosynthetic daily light integral (DLI) is low, especially in northern latitudes. Our objective was to quantify how propagation DLI influences subsequent growth and development of annual bedding plants. Cuttings of Angelonia angustifolia Benth. 'AngelMist White Cloud', Nemesia fruticans (Thunb.) Benth. 'Aromatica Royal', Osteospermum ecklonis (DC.) Norl. 'Voltage Yellow', and Verbena $\times$ hybrida Ruiz 'Aztec Violet' were harvested and propagated in a glass-glazed greenhouse. After callusing $\left(\approx 5 \mathrm{~mol} \cdot \mathrm{m}^{-2} \cdot \mathrm{d}^{-1}\right.$ for 7 days), cuttings of each species were placed under one of three different fixed-woven shadecloths providing $\approx 38 \%, 61 \%$, or $86 \%$ shade or no shade with $16 \mathrm{~h}$ of supplemental light for 14 days. Rooted cuttings were then transplanted into 11-cm containers and grown in a common greenhouse of $21 \pm 1{ }^{\circ} \mathrm{C}$ and DLI of $\approx 12 \mathrm{~mol} \cdot \mathrm{m}^{-2} \cdot \mathrm{d}^{-1}$ to identify any residual effects on subsequent growth and development during the finish stage. As DLI during propagation increased, time to first open flower decreased for Angelonia, Nemesia, Osteospermum, and Verbena. For example, time to flower for Angelonia and Osteospermum was hastened by 23 and 19 days, respectively, as DLI during propagation increased from 1.2 to $12.3 \mathrm{~mol} \cdot \mathrm{m}^{-2} \cdot \mathrm{d}^{-1}$. Our research can be used to predict growth and flowering under varying propagation DLIs for the cultivars of Angelonia, Nemesia, Osteospermum, and Verbena in the study.
\end{abstract}

Vegetatively propagated herbaceous bedding plants are produced in two distinct phases: a young plant stage, in which shoottip cuttings are rooted as liners, and a finish plant stage, in which the rooted young plants are transplanted into a larger finish container where they are grown until they become marketable (Klopmeyer, 2003). Vegetative propagation of bedding plants occurs from mid to

\footnotetext{
Received for publication 15 Mar. 2012. Accepted for publication 7 May 2012.

We gratefully acknowledge Diane Camberato, Rob Eddy, and Dan Hahn for greenhouse assistance; funding from growers providing support for Purdue University floriculture research; and support from the Purdue Agricultural Experiment Station. We thank Ball Horticultural Co. for plant material; Conrad Fafard, Inc. for substrate; Ludvig Svensson for shadecloth; J.R. Peters, Inc. and Everris for fertilizer; and the Indiana Flower Growers Association, Fred. C. Gloeckner Foundation, Inc., and USDA NIFA Specialty Crop Research Initiative award no. 2010-51181-21369 for support.

The use of trade names in this publication does not imply endorsement by Purdue University of products named nor criticism of similar ones not mentioned.

${ }^{1}$ Assistant Professor and Extension Specialist.

${ }^{2}$ To whom reprint requests should be addressed; e-mailrglopez@purdue.edu.
}

late winter and early spring when average daily ambient photosynthetic DLI is typically low, especially in northern latitudes (Currey et al., 2012; Lopez and Runkle, 2008). During this time, outdoor DLI can range from 5 to 20 $\mathrm{mol} \cdot \mathrm{m}^{-2} \cdot \mathrm{d}^{-1}$ (Korczynski et al., 2002). Shading, glazing materials, obstructions, and structures can further reduce DLI within propagation facilities to 2.5 to $10 \mathrm{~mol} \cdot \mathrm{m}^{-2} \cdot \mathrm{d}^{-1}$ (Oh et al., 2010) and can be as low as $1 \mathrm{~mol} \cdot \mathrm{m}^{-2} \cdot \mathrm{d}^{-1}$ during extended periods of overcast weather (Lopez and Runkle, 2008).

Many studies have been performed on the effects of increasing DLI during the young plant stage on root and shoot biomass, liner, and plug transplant quality (Currey et al., 2012; Enfield, 2002; Graper and Healy, 1991; Lopez and Runkle, 2008; Pramuk and Runkle, 2005; Rapaka et al., 2005; Torres and Lopez, 2011) or during the finish plant stage on flowering (Fausey et al., 2005; Islam et al., 2005; Loehrlein and Craig, 2004). Generally, increases in DLI during the propagation of seedlings and cuttings increased biomass accumulation, root growth, and transplant quality and hastened subsequent flowering. For example, increasing propagation DLI from 4.1 to $14.2 \mathrm{~mol} \cdot \mathrm{m}^{-2} \cdot \mathrm{d}^{-1}$ during the seedling stage increased shoot dry mass per internode linearly by $64 \%, 64 \%, 47 \%$, and $68 \%$ and plants subsequently flowered $4,10,12$, and
$12 \mathrm{~d}$ earlier in Tagetes patula L., Celosia argentea var. plumosa L., Impatiens walleriana Hook. f., and Viola $\times$ wittrockiana Gams., respectively (Pramuk and Runkle, 2005). When Petunia $\times$ hybrida Vilm.-Andr. and Viola seedlings were provided with supplemental light $\left(\approx 4\right.$ to $\left.5 \mathrm{~mol} \cdot \mathrm{m}^{-2} \cdot \mathrm{d}^{-1}\right)$ during the last two-thirds or entire young plant stage, shoot dry mass and number of leaves increased, whereas subsequent time to flower decreased. Similarly, increasing propagation DLI from 1.2 to $10.7 \mathrm{~mol} \cdot \mathrm{m}^{-2} \cdot \mathrm{d}^{-1}$ increased the root and shoot dry mass of Impatiens hawkeri Bull. 'Harmony White' cuttings by 1038 and $82 \%$, respectively, and subsequent time to flower decreased from 85 to $70 \mathrm{~d}$, respectively (Lopez and Runkle, 2008).

When outdoor DLI is low, the only way to increase DLI is to provide supplemental lighting from high-intensity discharge lamps (Oh et al., 2010). Lopez and Runkle (2008) indicated that DLI should be maintained between 4 to $6 \mathrm{~mol} \cdot \mathrm{m}^{-2} \cdot \mathrm{d}^{-1}$ when Impatiens hawkeri and Petunia cuttings are stuck and during callusing. The DLI should increase between 6 and $8 \mathrm{~mol} \cdot \mathrm{m}^{-2} \cdot \mathrm{d}^{-1}$ during root development and toning to obtain rapid, uniform rooting and high-quality rooted transplants that flower earlier, especially when cuttings are rooted during the darkest periods of the year. When ambient DLI is 8 to $10 \mathrm{~mol} \cdot \mathrm{m}^{-2} \cdot \mathrm{d}^{-1}$ or less, Oh et al. (2010) recommend using supplemental lighting during the two true leaf stage to produce good-quality plugs, rapid flowering, and energy savings.

One report (Lopez and Runkle, 2008) quantifies the effects of ambient DLI during vegetative cutting propagation on subsequent growth and development during the finish stage. However, the effects of using supplemental lighting to increase DLI during cutting propagation of a broader range of specialty herbaceous annual bedding plants has not been published. Therefore, our objective was to quantify the impact of supplemental DLI during cutting propagation on subsequent growth and development of four annual bedding plant species.

\section{Materials and Methods}

Plant material and culture. Cuttings of Angelonia angustifolia 'AngelMist White Cloud', Nemesia fruticans 'Aromatica Royal', Osteospermum ecklonis 'Voltage Yellow', and Verbena $\times$ hybrida 'Aztec Violet' were planted in $15-\mathrm{cm}$ (1.7-L volume) round containers filled with substrate comprised of (by volume) $80 \%$ sphagnum peatmoss and $20 \%$ perlite (Fafard 1P; Conrad Fafard, Inc., Agawam, MA) on 9 May 2010. Plants were irrigated with acidified water supplemented with water-soluble fertilizer to provide (in $\left.\mathrm{mg} \cdot \mathrm{L}^{-1}\right)$ : 200 nitrogen $(\mathrm{N}), 26$ phosphorus (P), 163 potassium $(\mathrm{K}), 50$ calcium $(\mathrm{Ca}), 20$ magnesium $(\mathrm{Mg}), 1.0$ iron $(\mathrm{Fe}), 0.5$ manganese $(\mathrm{Mn})$ and zinc $(\mathrm{Zn}), 0.24$ copper $(\mathrm{Cu})$, boron (B), and 0.1 molybdenum (Mo). Nutrients were supplied from a combination of two fertilizers, $900 \mathrm{mg} \cdot \mathrm{L}^{-1}$ (Peters Excel@ Cal-Mag 21N-2.2P-16.5K; The Scotts Co., 
Marysville, $\mathrm{OH}$ ) and $300 \mathrm{mg} \cdot \mathrm{L}^{-1}$ formulation (Peters Excel@ $15 \mathrm{~N}-2.2 \mathrm{P}-12.5 \mathrm{~K}$ ). Irrigation water was supplemented with $93 \%$ sulfuric acid (Brenntag, Reading, PA) at $0.08 \mathrm{mg} \cdot \mathrm{L}^{-1}$ to reduce alkalinity to $100 \mathrm{mg} \cdot \mathrm{L}^{-1}$ and $\mathrm{pH}$ to a range of 5.8 to 6.2 . Stock plants were maintained in a vegetative state by regularly pinching shoots and applying foliar sprays of solutions containing $250 \mathrm{mg} \cdot \mathrm{L}^{-1}$ ethephon (Florel; Lawn and Garden Products, Inc., Fresno, CA). Ethephon sprays stopped at least 3 weeks before cutting harvest.

Stock plants were grown in a glass-glazed greenhouse in West Lafayette, IN (lat. $40^{\circ} \mathrm{N}$ ) with an exhaust fan and evaporative-pad cooling and radiant hot-water heating controlled by an environmental computer (Maximizer Precision 10; Priva Computers Inc., Vineland Station, Ontario, Canada). The greenhouse day and night air temperature set points were $23{ }^{\circ} \mathrm{C}$ and were measured with an enclosed thermocouple (Watchdog 2450 Weather Station; Spectrum Technologies, Inc., Plainfield, IL). The photoperiod was a constant $16 \mathrm{~h}$ ( 0600 to $2200 \mathrm{HR}$ ) consisting of natural daylengths with day-extension lighting from high-pressure sodium lamps (HPS) that delivered a supplemental photosynthetic photon flux $(P P F)$ density of $100 \mu \mathrm{mol} \cdot \mathrm{m}^{-2} \cdot \mathrm{s}^{-1}$ at plant height [as measured with a quantum sensor (LI-COR Biosciences, Lincoln, NE)] from 1700 to $2200 \mathrm{HR}$. The greenhouse mean air temperature for stock plants was $23.2 \pm$ $1.2{ }^{\circ} \mathrm{C}$ and the mean DLI was $11.6 \pm 2.0$ $\mathrm{mol} \cdot \mathrm{m}^{-2} \cdot \mathrm{d}^{-1}$ (average daily temperature \pm the temperature SD).

Cutting harvest. On 4 Sept. 2010, 16 Oct. 2010, and 11 Jan. 2011, 40 uniform $2.5-\mathrm{cm}$ shoot-tip cuttings were harvested from each species of stock plant. The cuttings were then placed in 105-cell propagation trays (individual cell volume $28 \mathrm{~mL}$; T.O. Plastics, Inc., Clearwater, MN) filled with a propagation substrate composed of (v/v) 50\% soilless substrate (Fafard 1P) and 50\% coarse perlite (Strong-Lite Coarse Perlite; Sun Gro Horticulture, Bellevue, WA). Cuttings were sprayed to runoff with a solution containing $300 \mathrm{mg} \cdot \mathrm{L}^{-1}$ non-ionic surfactant (CapSil; Aquatrols, Paulsboro, NJ) so water would not accumulate on the plant foliage.

Propagation environment and culture. All cuttings were rooted in a glass-glazed greenhouse under a 16-h photoperiod with an air temperature set point of $23{ }^{\circ} \mathrm{C}$, and the DLI was maintained at $\approx 5 \mathrm{~mol} \cdot \mathrm{m}^{-2} \cdot \mathrm{d}^{-1}$ during callusing. Enclosed resistance-based sensors placed below the mist and sensors (External Temperature Sensor; Spectrum Technologies, Inc.) inserted into the substrate were used to measure air and substrate temperatures, respectively, in each treatment every $30 \mathrm{~s}$ and averages were logged every $15 \mathrm{~min}$ by a data logger (Watchdog 2800 Weather Station; Spectrum Technologies, Inc.). Two amplified quantum sensors placed above the mist nozzles (SQ-212; Apogee Instruments, Inc., Logan, UT) measured PPF every $30 \mathrm{~s}$ under each light treatment and the average of each sensor was logged every $15 \mathrm{~min}$ by a data logger (Watchdog 2800 Weather
Station). For the three periods from harvest through callusing, the average air temperatures were $21.3 \pm 0.5,20.9 \pm 0.8$, and $20.7 \pm$ $1.1{ }^{\circ} \mathrm{C}$; the average substrate temperatures were $22.7 \pm 0.5,22.6 \pm 0.9$, and $22.4 \pm 1.5^{\circ} \mathrm{C}$; and the average DLIs were $5.0 \pm 0.9,4.7 \pm$ 1.2 , and $4.8 \pm 0.7 \mathrm{~mol} \cdot \mathrm{m}^{-2} \cdot \mathrm{d}^{-1}$, respectively.

After $7 \mathrm{~d}$ of callusing, 10 cuttings of each species were placed under DLI treatments that were created using no shade or shadecloth providing $\approx 38 \%, 61 \%$, or $86 \%$ or no shade (XLS F-14, -15, or -16; Ludvig Svensson, Inc., Charlotte, NC) under ambient daylight supplemented with $79 \pm 8,44 \pm 5,33 \pm 5$, or $13 \pm 2 \mu \mathrm{mol} \cdot \mathrm{m}^{-2} \cdot \mathrm{s}^{-1}$, respectively, delivered from HPS lamps from 0600 to $2000 \mathrm{HR}$. Every 20 min, 4 s of mist was applied consisting of acidified water supplemented with a watersoluble fertilizer (Jack's LX 16N-0.94P12.3K Plug Formula for High Alkalinity Water; J.R. Peters, Inc., Allentown, PA) providing (in $\mathrm{mg} \cdot \mathrm{L}^{-1}$ ) with each misting event: $50 \mathrm{~N}, 5 \mathrm{P}, 39 \mathrm{~K}, 9 \mathrm{Ca}, 4.7 \mathrm{Mg}$, $0.05 \mathrm{~B}, 0.025 \mathrm{Cu}, 0.25 \mathrm{Fe}, 0.125 \mathrm{Mn}, 0.025$ $\mathrm{Mo}$, and $0.125 \mathrm{Zn}$. Six days after transfer of cuttings, misting frequency was reduced to every $30 \mathrm{~min}$ beginning and ending $2 \mathrm{~h}$ before and after the photoperiod, respectively; $8 \mathrm{~d}$ after cutting, transfer misting was reduced to begin and end $1 \mathrm{~h}$ before and after the photoperiod. Ten days after the placement of cuttings under DLI treatments, the use of mist was discontinued and cuttings were handirrigated daily with acidified water supplemented with water-soluble fertilizer as described in the previous "Plant Material and Culture" section. Environmental data were measured as previously described and are reported in Table 1.

Plant finishing culture. After $21 \mathrm{~d}$ in propagation DLI treatments, nine plants of each species from each DLI treatment were transplanted on 25 Sept. 2010, 6 Nov. 2010, and 1 Feb. 2011 into $11-\mathrm{cm}$ diameter round containers (602-mL volume) filled with a peat-based substrate (Fafard 1P). Plants were hand-watered with water supplemented with water-soluble fertilizer (combination of fertilizers as previously described) to provide (in $\mathrm{mg} \cdot \mathrm{L}^{-1}$ ): $200 \mathrm{~N}, 26 \mathrm{P}, 163 \mathrm{~K}, 50 \mathrm{Ca}$, $20 \mathrm{Mg}$, and micronutrients. Leaf temperature was measured using infrared temperature sensors (Temperature/Transmitter model OS1361; Omega Engineering Inc., Stamford, CT). The plants were grown at $21{ }^{\circ} \mathrm{C}$ under a $16-\mathrm{h}$ photoperiod (as described previously) and environmental data are reported in Table 2.

Data collection. Time to flower from the time of transplant, number of flower buds (greater than $2 \mathrm{~mm}$ in diameter), number of lateral branches (greater than $2 \mathrm{~cm}$ in length), the number of nodes below the first open flower, and plant height from the substrate level to the tip of the longest shoot were recorded on the date the first flower opened on each plant. For Verbena, each inflorescence was recorded as a flower. Shoot dry mass was recorded after drying in an oven at $70{ }^{\circ} \mathrm{C}$ for 1 week.

Data analysis. The experiment used a randomized complete block design in a factorial arrangement. The factors were DLI (12 levels) and species (four levels). The experiment was repeated twice over time with nine samples (individual cuttings) per species per DLI per propagation date. Cuttings were randomly assigned to each DLI treatment, and DLI treatments were randomized between propagation dates within the greenhouse. Data were analyzed using regression analyses (Sigma Plot 11.0; Systat Software, Inc., San Jose, CA) with DLI as the independent variable.

\section{Results}

Flowering. The number of days from transplant to first open flower decreased linearly as propagation DLI increased for Angelonia and Osteospermum. For example, subsequent time to flower was hastened by 23 and $19 \mathrm{~d}$, respectively, as DLI during propagation increased from 1.2 to $12.3 \mathrm{~mol} \cdot \mathrm{m}^{-2} \cdot \mathrm{d}^{-1}$ (Figs. 1A and 1C). As DLI increased from 1.2 to $12.3 \mathrm{~mol} \cdot \mathrm{m}^{-2} \cdot \mathrm{d}^{-1}$, a quadratic decrease in the number of days from transplant to the first open flower was observed for Verbena and Nemesia (Figs. 1B and 1D). The number of buds at first open flower for Angelonia, Nemesia, and Verbena was not influenced by the DLI during propagation (data not shown). However, in Osteospermum, bud number decreased by 14.1 as propagation DLI increased from 1.2 to $12.3 \mathrm{~mol} \cdot \mathrm{m}^{-2} \cdot \mathrm{d}^{-1}$. The number of nodes below the first open flower for Angelonia, Nemesia, and Verbena was not influenced by propagation DLI (data not shown). However, the number of nodes below the first open flower for Osteospermum decreased by 15.7 as propagation DLI increased from 1.2 to $12.3 \mathrm{~mol} \cdot \mathrm{m}^{-2} \cdot \mathrm{d}^{-1}$ (data not shown).

Growth. Shoot dry mass at flowering of all species decreased as propagation DLI increased. For example, as propagation DLI increased from 1.2 to $12.3 \mathrm{~mol} \cdot \mathrm{m}^{-2} \cdot \mathrm{d}^{-1}$, shoot dry mass of Angelonia, Nemesia, and Osteospermum decreased linearly by $0.9,1.5$, and 3.4 g, respectively (Fig. 1E-G). As DLI during propagation increased from 1.2 to $12.3 \mathrm{~mol} \cdot \mathrm{m}^{-2} \cdot \mathrm{d}^{-1}$, final plant height at flowering decreased for Angelonia and Osteospermum by 61 and $35 \mathrm{~mm}$, respectively (Figs. 2A and 2C). Height of Verbena was an exception to this trend and was unaffected by propagation DLI (Fig. 2D). Branch number of Angelonia, Osteospermum, and Verbena decreased as propagation DLI increased from 1.2 to $12.3 \mathrm{~mol} \cdot \mathrm{m}^{-2} \cdot \mathrm{d}^{-1}$ by $1.8,10.9$, and 1.0 , respectively (Figs. 2A, 2B, and 2D). However, branch number of Nemesia was unaffected by propagation DLI.

\section{Discussion}

To properly schedule bedding plants to flower within a predetermined and narrow market window for spring sales, greenhouse operations must intensively manage environmental factors such as temperature and light (Heins et al., 2000). Therefore, knowledge of how DLI during propagation influences crop timing and quality is crucial because an 


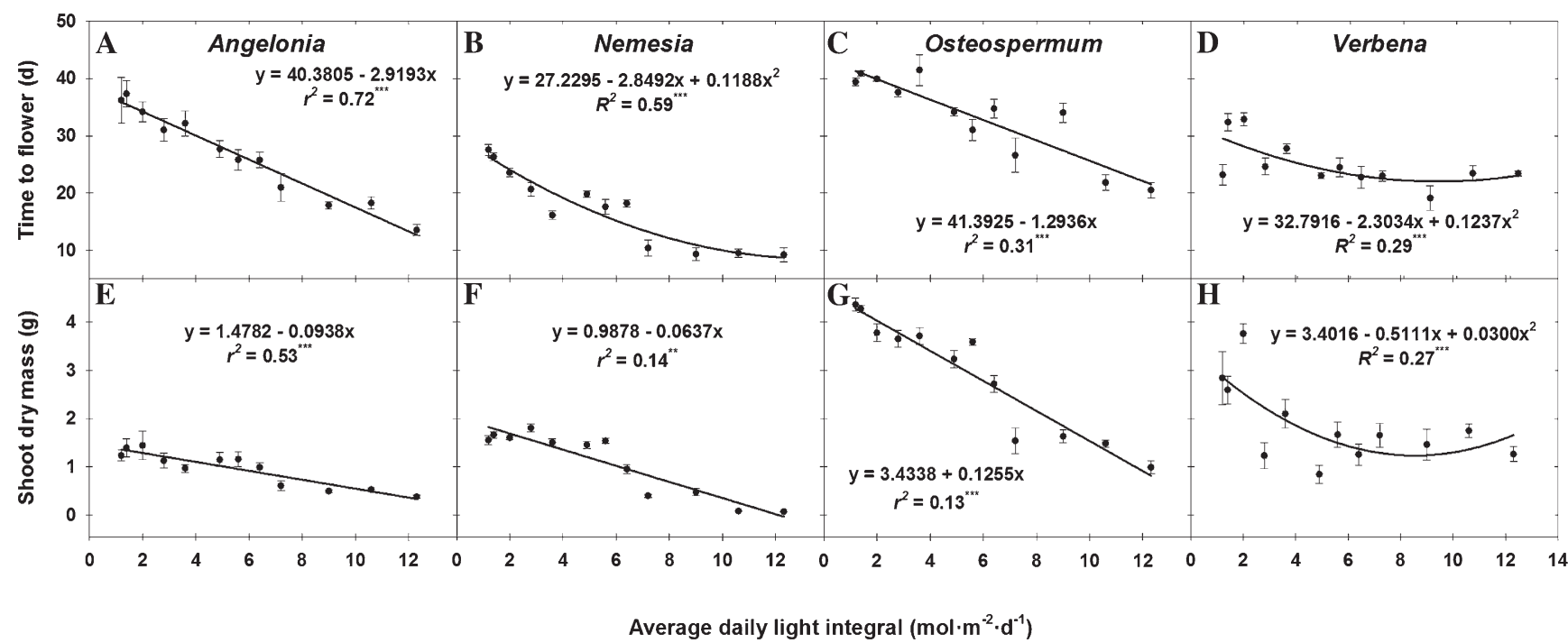

Fig. 1. (A-H) Relationships between mean photosynthetic daily light integral during propagation and time to flower from transplant and shoot dry mass at first flowering for Angelonia, Nemesia, Osteospermum, and Verbena. Each symbol represents the mean of nine plants in each treatment and error bars represent sDs of the mean. Regression lines are presented for significant correlations only with corresponding $r^{2}$ and $R^{2}$ presented. NS, *,**,*** indicate nonsignificant or significant at $P \leq 0.05,0.01$, or 0.001 , respectively.

Table 1. Average daily greenhouse air and substrate temperature $\left({ }^{\circ} \mathrm{C}\right)$ and daily light integral (DLI; $\mathrm{mol} \cdot \mathrm{m}^{-2} \cdot \mathrm{d}^{-1}$ ) during root development (from callusing to transplant) of seven vegetatively propagated annuals under $\approx 38 \%, 61 \%$, or $86 \%$ shade (XLS-14, -16, or -18; Ludvig Svensson, Inc., Charlotte, NC) or no shade $(0 \%){ }^{2}$

\begin{tabular}{lcccc}
\hline & & \multicolumn{2}{c}{ Temperature $\left({ }^{\circ} \mathrm{C}\right)$} & \\
\cline { 2 - 4 } Propagation date & Shade $(\%)$ & Air & Substrate & DLI $\left(\mathrm{mol} \cdot \mathrm{m}^{-2} \cdot \mathrm{d}^{-1}\right)$ \\
\hline 4 Sept. 2010 & 0 & $22.2 \pm 0.8$ & $22.6 \pm 0.5$ & $12.3 \pm 1.5$ \\
& 38 & $21.9 \pm 0.8$ & $22.1 \pm 0.3$ & $7.2 \pm 1.2$ \\
& 61 & $22.1 \pm 0.7$ & $22.2 \pm 0.7$ & $5.6 \pm 1.2$ \\
17 Oct. 2010 & & $21.9 \pm 0.8$ & $23.7 \pm 1.1$ & $2.0 \pm 0.4$ \\
& 0 & $22.4 \pm 0.3$ & $23.1 \pm 0.4$ & $10.6 \pm 1.4$ \\
& 38 & $22.3 \pm 0.6$ & $22.4 \pm 0.4$ & $6.4 \pm 0.8$ \\
& 61 & $21.6 \pm 0.8$ & $22.0 \pm 0.3$ & $3.6 \pm 0.4$ \\
11 Jan. 2011 & 86 & $21.9 \pm 0.5$ & $22.1 \pm 0.3$ & $1.4 \pm 0.2$ \\
& & & & \\
& 0 & $21.8 \pm 0.6$ & $22.4 \pm 0.6$ & $9.0 \pm 0.9$ \\
& 38 & $21.9 \pm 0.7$ & $21.9 \pm 0.2$ & $4.9 \pm 0.8$ \\
& 61 & $21.8 \pm 0.6$ & $22.0 \pm 0.3$ & $2.8 \pm 0.8$ \\
& 86 & $22.4 \pm 0.7$ & $23.0 \pm 0.6$ & $1.2 \pm 0.4$ \\
\hline
\end{tabular}

${ }^{\mathrm{z}}$ Treatments consisted of ambient daylight supplemented with $79 \pm 8,44 \pm 5,33 \pm 5$, or $13 \pm 2 \mu \mathrm{mol} \cdot \mathrm{m}^{-2} \cdot \mathrm{s}^{-1}$ (average $\pm \mathrm{SD}$ ), respectively, provided by high-pressure sodium lamps from 0600 to $2000 \mathrm{HR}$.

increasing number of greenhouse growers are vegetatively propagating annual bedding plants. Additionally, species-specific and, in some cases, cultivar-specific guide lines are needed to efficiently schedule and root vegetatively propagated bedding plant crops to meet market dates.

Management of DLI during seed and cutting propagation and finishing can reduce production time and increase crop quality (Currey et al., 2012; Fausey et al., 2005; Faust et al., 2005; Lopez and Runkle, 2008; Oh et al., 2010). Results from this study are in agreement with findings of Lopez and Runkle (2008) who quantified the effects of ambient DLI during propagation on subsequent development of Impatiens hawkeri and Petunia. In both studies, time to flower decreased as DLI during propagation increased. For example, in the current study, as DLI (supplemented with HPS lamps) during propagation increased from 1.2 to $12.3 \mathrm{~mol} \cdot \mathrm{m}^{-2} \cdot \mathrm{d}^{-1}$, time to flower decreased linearly for Angelonia and Osteospermum by 23 and 19 d. Similarly, Lopez and Runkle (2008) reported that as ambient propagation DLI increased from 1.4 to $10.7 \mathrm{~mol} \cdot \mathrm{m}^{-2} \cdot \mathrm{d}^{-1}$, time to flower decreased by 21 and $22 \mathrm{~d}$ for Petunia 'Tiny Tunia Violet Ice' and 'Supertunia Mini Purple', respectively.

Shoot dry mass is often considered an indicator of plant quality (Fausey et al., 2005; Lopez and Runkle, 2008; Oh et al., 2010; Pramuk and Runkle, 2005). Shoot dry mass is a reliable quantitative measurement of plant size and fullness. Although increasing propagation DLI resulted in decreased flowering time (which is also a quality parameter), the quality of the plants may be reduced by some standards as a result of the decrease in shoot dry mass. This tradeoff between rapid flowering and quality is consistent with several other studies (Lopez and Runkle, 2008; Oh et al., 2010; Pramuk and Runkle, 2005). For example, the shoot dry mass for Petunia 'Tiny Tunia Violet Ice' and 'Supertunia Mini Purple' at first open flower decreased by $\approx 1.5$ and $1.0 \mathrm{~g}$ as propagation DLI increased from $\approx 1$ to $11 \mathrm{~mol} \cdot \mathrm{m}^{-2} \cdot \mathrm{d}^{-1}$. Shoot dry mass at first open flower may be reduced as a result of increased propagation DLI, which in certain instances may be desirable. For example, a decreased shoot dry mass may be desirable when using a smaller finishing container. An alternative method of achieving a smaller finished plant is the use of a chemical plant growth retardant such as ethephon, which can induce floral senescence, abscission, and abortion, thus delaying time to flower and promoting shoot growth. However, caution must be exercised because exogenous ethephon applications may result in smaller root systems (unpublished data). Therefore, applications should not be made until cuttings are in the final stages of rooting after adequate root growth has occurred.

The effect of DLI on height or stem elongation at the first open flower was not consistent among the species in this study. For example, height of Angelonia and Osteospermum and stem elongation of Nemesia at the first open flower decreased as propagation DLI increased from 1.2 to $12.3 \mathrm{~mol} \cdot \mathrm{m}^{-2} \cdot \mathrm{d}^{-1}$. However, stem elongation of Verbena was not significantly influenced by propagation DLI. Similarly, Lopez and Runkle (2008) reported the height at the first open flower of Petunia and Impatiens hawkeri was not influenced by propagation DLI.

In addition to time to flower, increasing DLI in propagation impacted other flowering characteristics. We observed variability in flower bud number in response to propagation DLI among species, which is consistent with results from Lopez and Runkle (2008). In the current study, flower bud number was 


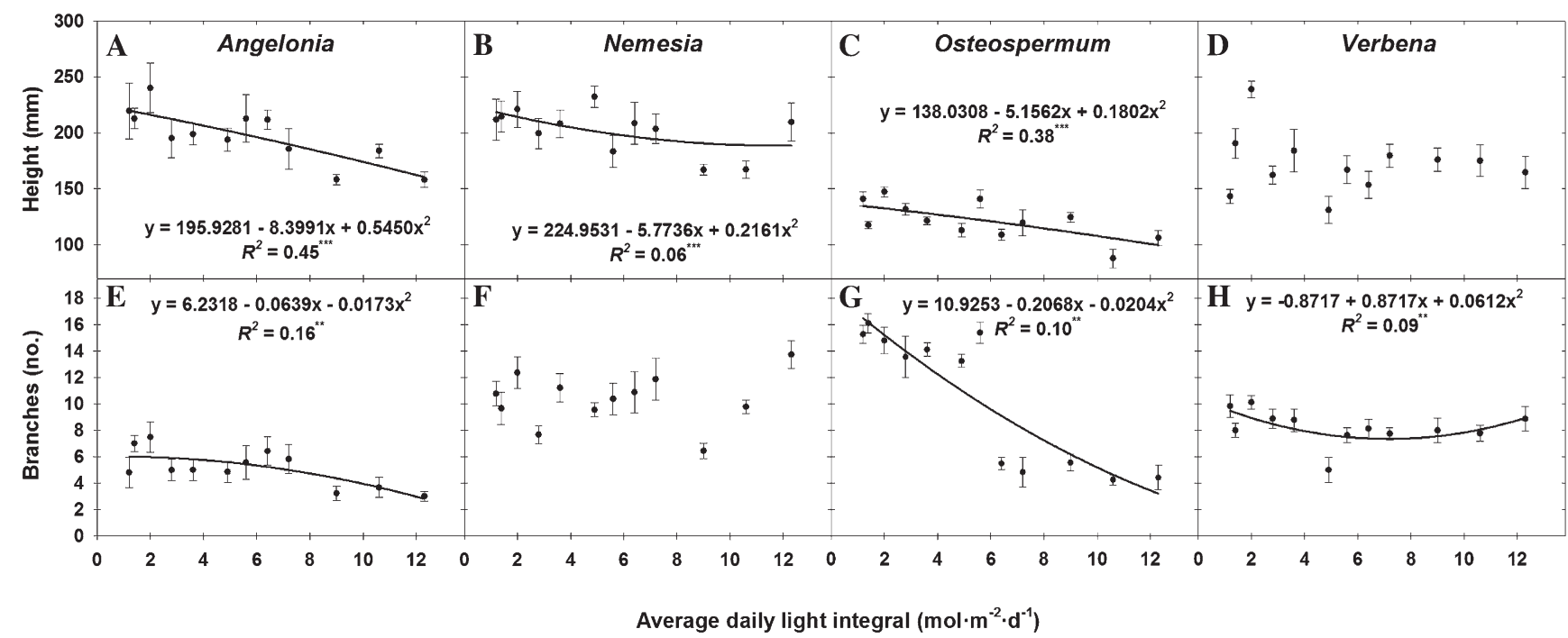

Fig. 2. (A-H) Relationships between mean photosynthetic daily light integral during propagation and height and branch number at first flowering for Angelonia, Nemesia, Osteospermum, and Verbena. Each symbol represents the mean of nine plants in each treatment and error bars represent ses of the mean. Regression lines are presented for significant correlations only with corresponding $r^{2}$ and $R^{2}$ presented. Ns, $*, * *, * * *$ indicate nonsignificant or significant at $P \leq 0.05$, 0.01 , or 0.001 , respectively.

Table 2. Average daily greenhouse air and leaf temperature $\left({ }^{\circ} \mathrm{C}\right)$ and daily light integral $\left(\mathrm{DLI} ; \mathrm{mol} \cdot \mathrm{m}^{-2} \cdot \mathrm{d}^{-1}\right)$ during the subsequent finish stage of four vegetatively propagated annuals under $\approx 38 \%, 61 \%$, or $86 \%$ shade (XLS-14, -16, or -18; Ludvig Svensson, Inc., Charlotte, NC) or no shade (0\%). ${ }^{2}$

\begin{tabular}{llccc}
\hline & & \multicolumn{2}{c}{ Temperature $\left({ }^{\circ} \mathrm{C}\right)$} & \\
\cline { 3 - 4 } Propagation date & Transplant date & Air & Leaf & DLI $\left(\mathrm{mol} \cdot \mathrm{m}^{-2} \cdot \mathrm{d}^{-1}\right)$ \\
\hline 4 Sept. 2010 & 25 Sept. 2010 & $20.9 \pm 0.87$ & $22.6 \pm 1.3$ & $11.9 \pm 3.3$ \\
17 Oct. 2010 & 06 Nov. 2010 & $21.2 \pm 0.43$ & $21.9 \pm 1.2$ & $11.6 \pm 3.0$ \\
11 Jan. 2011 & 01 Feb. 2011 & $22.0 \pm 0.76$ & $22.4 \pm 1.9$ & $11.8 \pm 1.9$ \\
\hline
\end{tabular}

${ }^{2}$ Treatments consisted of ambient daylight supplemented with $45,28,11$, or $81 \mu \mathrm{mol} \cdot \mathrm{m}^{-2} \cdot \mathrm{s}^{-1}$ on average provided by high-pressure sodium lamps from 0600 to $2000 \mathrm{HR}$.

not influenced by increasing propagation DLI in any species with the exception of Osteospermum. Although flower bud number of Osteospermum at first open flower decreased as propagated DLI increased, we do not believe that increased flower bud number is a reflection of greater floral induction. Rather, plants propagated under lower DLIs (less than $6 \mathrm{~mol} \cdot \mathrm{m}^{-2} \cdot \mathrm{d}^{-1}$ ) flowered $\approx 20$ to $40 \mathrm{~d}$ after transplant and had more branches with terminal flowers. Similarly, Lopez and Runkle (2008) reported that flower bud number of Petunia 'Double Wave Spreading Rose' and three cultivars of Impatiens hawkeri was not influenced by propagation DLI, whereas flower bud number of Petunia 'Tiny Tunia Violet Ice' and 'Supertunia Mini Purple' decreased as propagation DLI increased.

The number of nodes beneath the first flower in Osteospermum decreased as propagation decreased. With these data, we are able to classify Osteospermum as having a facultative irradiance (FI) response based on a reduced node number below the inflorescence in response to increasing DLI (Erwin and Warner, 2002; Mattson and Erwin, 2005). However, there were no differences in the number of flower buds or nodes below the first flower or inflorescence for Angelonia, Nemesia, and Verbena. This would suggest that cuttings were induced to flower at the same time and to a similar degree based on node number and flower number, respectively. Additionally, the fact that flowering occurred in as little as 2 weeks after transplant for cuttings propagated under high DLIs suggests that floral induction and initiation had likely occurred before or early in propagation. However, there were no significant differences in plant temperature during propagation under different DLIs (data not shown) and cuttings were finished in a common environment. Preliminary data indicate that cuttings propagated under higher DLIs have higher photosynthetic rates. For example, photosynthesis of 'Magnum Salmon' Impatiens hawkeri was $2.0,4.5$, and $6.3 \mu \mathrm{mol} \cdot \mathrm{m}^{-2} \cdot \mathrm{s}^{-1}$, respectively, for cuttings propagated under $\approx 2.5,8.5$, and $15.6 \mathrm{~mol} \cdot \mathrm{m}^{-2} \cdot \mathrm{d}^{-1}$, respectively (unpublished data). Therefore, flower bud development for Angelonia, Nemesia, and Verbena may have been a function of carbohydrate source rather than temperature. Developing flower buds are carbohydrate sinks. For example, development and retention of flower buds of Capsicum annuum L. was related to carbohydrate accumulation (Aloni et al., 1996). Lopez and Runkle (2008) hypothesized that low DLIs are needed to accumulate more photosynthates or increase net photosynthesis to promote flower bud initiation or continued development of initiated buds and our data from this study may strengthen that hypothesis.

\section{Conclusions}

Data from this study may be used to predict how propagation DLI can influence subsequent growth and development of Angelonia, Nemesia, Osteospermum, and Verbena (i.e., time to flower, shoot dry mass, height, bud number, and branch number). Further studies are needed to quantify the effects of the interaction between propagation and finishing DLI across a wider range of plant species. This will help to create guidelines that commercial growers can follow to maximize efficiency during the propagation and finish environments to produce high-quality liners and flowering plants.

Lopez and Runkle (2008) recommend a propagation DLI of between 6 and $8 \mathrm{~mol} \cdot \mathrm{m}^{-2} \cdot \mathrm{d}^{-1}$ for Petunia and Impatiens hawkeri after roots have initiated to ensure uniform cuttings with accelerated flowering. However, when the results of the current study are taken together with those reported by Currey et al. (2012), we recommend greenhouse propagators maintain a DLI of $\approx 10 \mathrm{~mol} \cdot \mathrm{m}^{-2} \cdot \mathrm{d}^{-1}$ during root development with the use of supplemental lighting after callusing to increase both growth and quality of rooted cuttings and reduce subsequent time to flower.

\section{Literature Cited}

Aloni, B., L. Karni, Z. Zaidman, and A.A. Schaffer. 1996. Changes of carbohydrates in pepper (Capsicum annuum L.) flowers in relation to their abscission under different shading regimes. Ann. Bot. (Lond.) 78:163-168.

Currey, C.J., V.A. Hutchinson, and R.G. Lopez. 2012. Growth, morphology, and quality of rooted cuttings of several herbaceous annual bedding plants are influenced by photosynthetic daily light integral during root development. HortScience 47:25-30.

Enfield, A.L. 2002. Flower induction and cultural requirements for quick-cropping of the herbaceous perennials Veronica spicata, Phlox 
paniculata, Leucanthemum ×superbum, Achillea, Gaura lindheimeri, and Campanula. MS thesis, Dept. of Horticulture, Michigan State Univ., East Lansing, MI.

Erwin, J.E. and R.M. Warner. 2002. Determination of photoperiodic response group and effect of supplemental irradiance on flowering of several bedding plant species. Acta Hort. 580:95-100.

Fausey, B.A., R.D. Heins, and A.C. Cameron. 2005. Daily light integral affects flowering and quality of greenhouse-grown Achillea, Guara, and Lavandula. HortScience 40:114118.

Faust, J.E., V. Holcombe, N.C. Rajapakse, and D.R. Layne. 2005. The effect of daily light integral on bedding plant growth and flowering. HortScience 40:645-649.

Graper, D.F. and W. Healy. 1991. High pressure sodium irradiation and infrared radiation accelerate Petunia seedling growth. J. Amer. Soc. Hort. Sci. 116:435-438.

Heins, R.D., B. Liu, and E.S. Runkle. 2000. Regulation of crop growth and development based on environmental factors. Acta Hort. 514:1322.

Islam, N., G.G. Patil, and H.R. Gislerød. 2005. Effect of photoperiod and light integral on flowering and growth of Eustoma grandiflorum (Raf.). Shinn. Sci. Hort. 103:441-451.

Klopmeyer, M., M. Wilson, and A. Whealy. 2003. Propagating vegetative crops, p. 165-184. In Hamrick, D. (ed.). Ball redbook. 17th Ed. Ball Publishing, Batavia, IL.

Korczynski, P.C., J. Logan, and J.E. Faust. 2002. Mapping monthly distribution of daily light integrals across the contiguous United States. HortTechnology 12:12-16.

Loehrlein, M.M. and R. Craig. 2004. The effect of daily light integral on floral initiation of Pelargonium $\times$ domesticum L.H. Bailey. HortScience 39:529-532.

Lopez, R.G. and E.S. Runkle. 2008. Photosynthetic daily light integral during propagation influences rooting and growth of cuttings and subsequent development of New Guinea impatiens and petunia. HortScience 43:2052-2059.
Mattson, N.S. and J.E. Erwin. 2005. The impact of photoperiod and irradiance on flowering of several herbaceous ornamentals. Scientia Hort. 104:275-292.

Oh, W., E.S. Runkle, and R.M. Warner. 2010. Timing and duration of supplemental lighting during the seeding stage influence quality and flowering in Petunia and Pansy. HortScience 45:1332-1337.

Pramuk, L.A. and E.S. Runkle. 2005. Modeling growth and development of Celosia and Impatiens in response to temperature and photosynthetic daily light integral. J. Amer. Soc. Hort. Sci. 130:813-818.

Rapaka, V.K., B. Bessler, M. Schreiner, and U. Druge. 2005. Interplay between initial carbohydrate availability, current photosynthesis, and adventitious root formation in Pelargonium cuttings. Plant Sci. 168:1547-1560.

Torres, A.P. and R.G. Lopez. 2011. Photosynthetic daily light integral during propagation of Tecoma stans influences seedling rooting and growth. HortScience 46:282-286. 